\title{
Introducing a local careers fair to help support foundation year 2 doctors with their career choices: a quality improvement project
}

\author{
Authors: Arani Vivekanantham, ${ }^{A}$ Amit Chawla, ${ }^{B}$ Petra Hanson, ${ }^{B}$ Arham Qureshi, ${ }^{B}$ Hisham Omer ${ }^{B}$ and Clare Ingram ${ }^{B}$
}

\section{Introduction}

The number of foundation year 2 doctors (FY2s) entering specialty training straight after the Foundation Programme is decreasing each year. One reason for this is trainees' dissatisfaction with training; many feel that their work predominantly centres on service provision, with minimal opportunities for training. This, combined with $\mathrm{FY} 2 \mathrm{~s}$ expecting to make choices about future specialties after only 18 months of clinical experience, means that there is a need for effective and early career advice to be integrated into the Foundation curriculum.

\section{Methods}

Over a 4-month period, an online questionnaire was designed and distributed to the FY2s to find out about their experiences of the FY2 teaching programme and level of careers advice/support received.

\section{Results}

The overall response rate was 40\% (44/111). Seventy-four per cent felt that the Foundation teaching programme had not given them sufficient careers guidance and $81 \%$ wanted more advice about careers. Moreover, $60 \%$ felt that the careers sessions currently in the curriculum were given at the wrong time of year, eg after application deadlines. In response to this feedback, a local careers fair, with representatives from a variety of medical and surgical specialties, was introduced to help support FY2s in their career choices.

Feedback assessing the FY2 trainees' satisfaction, particularly with regards to the amount/quality of careers guidance received and how this informed their future career choices, was collected before and after the careers fair in the form of an anonymised, voluntary form consisting of Likert-based and free-text responses. The feedback showed a significant improvement in trainees' satisfaction; the majority reported that the careers event helped them to decide their future career and recommended that this event to be run for future cohorts. Specific comments included 'it was really helpful to be able to talk to doctors who have gone through the same process and to find out from them what the experience was like'.

\section{Conclusion}

Introducing a careers fair at a local hospital helped to guide and inform FY2s' career choices, and significantly improved their satisfaction with the careers guidance they received. There are plans for this intervention to be repeated for future cohorts of doctors, both locally and nationally. Further work is planned to assess the impact of the careers fair on the choices and number of FY2 doctors applying for training.
Authors: ${ }^{A}$ Arthritis Research UK Centre for Epidemiology, University of Manchester, Manchester, UK; ${ }^{B}$ University Hospitals of Coventry and Warwickshire NHS Trust, Warwickshire, UK 